\title{
Testicular Schistosomiasis Caused by Schistosoma mansoni: A Case Report from Brazil
}

\author{
Roberto Iglesias Lopes, Kátia Ramos Leite, Décio Prando and Roberto Nicomedes Lopes
}

Department of Urology, Sociedade Beneficente Hospital Sírio Libanês; São Paulo, SP, Brazil

\begin{abstract}
Testicular schistosomiasis by Schistosoma mansoni is exceedingly rare, with only 11 cases reported in PubMed. We report a new case from Brazil. A 31-year-old man from the northeast region of the country presented with a $2 \mathrm{~cm}$ nodule in the right testis. Ultrasonography showed a well-delimited hypoechoic tumor, suggestive of a granulomatous lesion. Magnetic resonance imaging revealed an irregular tunica albuginea signal. A biopsy showed interstitial tissue with schistosome ova and granuloma formation. The nodule was excised, and the patient was treated with oxamniquine. He has remained symptom free for 10 years. A testicular nodule should raise suspicion of numerous pathologies, including schistosomiasis. Treatment should include therapy with oxamniquine or praziquantel, and nodule excision should be done whenever possible.

Key-Words: Testis, schistosomiasis, orchiectomy.
\end{abstract}

Schistosomiasis is one of the most important communicable diseases, both for public health and because of its socio-economic impact in the developing world. Currently, 200 million people are infected worldwide, among which 120 million are symptomatic and 20 million have severe disease [1].

Different species of Schistosoma are known to infect humans [1]. Infection with Schistosoma mansoni, S. japonicum, S. mekongi and $S$. intercalatum is associated with chronic hepatic and intestinal fibrosis. Schistosoma haematobium infection results in fibrosis, structuring and calcification of the urinary tract.

Schistosomiasis results from the host's immune responses to schistosome eggs, including a granulomatous reaction evoked by the antigens they secrete. Most granulomas develop at the sites of maximal accumulation of the eggs, which are the intestine and the liver for $S$. mansoni, since worms locate in the portal mesenteric system.

Testicular schistosomiasis caused by $S$. mansoni is exceedingly rare; till now only 11 cases have been reported in PubMed/Medline.

\section{Case Report}

A 31-year-old man presented with a $2 \mathrm{~cm}$ nodule in the right testis that he had noticed two months before. The patient was from the northeast region of Brazil, which is endemic for schistosomiasis. Leucocyte counts, human chorionic gonadotrophin and alphafetoprotein were normal. Ultrasonography of the testis showed a well-delimited elliptic hypoechoic tumor with adjacent hyperechogenicity suggestive of a granulomatous lesion. Magnetic resonance imaging (MRI) revealed an irregular tunica albuginea signal on the posterior side of the right testis (Figure 1). Although

Received on 18 February 2007; revised 5 August 2007.

Address for correspondence: Dr. Roberto Iglesias Lopes. Rua Baronesa de Itu 721 apto 121 Higienópolis, São Paulo, Brazil. Zip code: 01231-001. Telephone/Fax: (011) 366682 66. E-mail: robertoiglesias@terra.com.br.

The Brazilian Journal of Infectious Diseases 2007;11(5):523-524. (C) 2007 by The Brazilian Journal of Infectious Diseases and Contexto Publishing. All rights reserved. regional heterogeneity was observed, there was no evidence of a focal nodular lesion. A biopsy of the nodule showed interstitial tissue with schistosome ova and granuloma formation. The seminiferous epithelium and spermatogenesis were preserved. The nodule was excised and pathological evaluation was characteristic for schistosomiasis. Schistosome eggs with their lateral spines were observed to be surrounded by granulomas (Figure 2), and Schistosoma mansoni eggs were found in the stool. The patient was treated with oxamniquine and has remained symptom free for 11 years.

\section{Discussion}

Schistosoma mansoni has a life cycle characterized by three stages: an egg phase, followed by a free-swimming larval form, called cercaria, and finally an adult worm. The two latter phases require different host types.

Cercaria penetrate the skin of humans, and after they shed their tails, the resulting schistosomules enter capillaries and lymphatic vessels en route to the lungs. There, they reach the portal venous system, where they mature and mate. In a $S$. mansoni infection, adult worms migrate to superior mesenteric veins, where egg production commences and continues for the life of the worms (usually three to five years). Eggs pass from the lumen of blood vessels into adjacent tissues and are shed in the feces. They hatch in the feces, releasing miracidia that infect freshwater snails (Biomphalaria spp.). Cercaria are then released into water, completing the cycle [1].

Since $S$. mansoni worms locate in the portal mesenteric system, testicular involvement is exceedingly rare. Testicular schistosomiasis is attributed to the migration of eggs through venous channels between the internal spermatic and mesenteric veins [2,3].

In an autopsy study in an endemic area in Brazil, testicular involvement was found in $3.2 \%$ of the schistosomiasis cases, which shows that these lesions are commonly subclinical [4]. Clinically, testicular schistosomiasis caused by S. mansoni presented as an unilateral testicular swelling in seven cases [3,5-10], infertility in two cases $[9,11]$ and a nodule (in the right testis) in two cases $[2,12]$. Swelling was on the right side in three cases $[3,5,8]$ and on the left in four reports $[6,7,9,10]$. 
Figure 1. Irregular tunica albuginea signal (circled area) in the MRI.

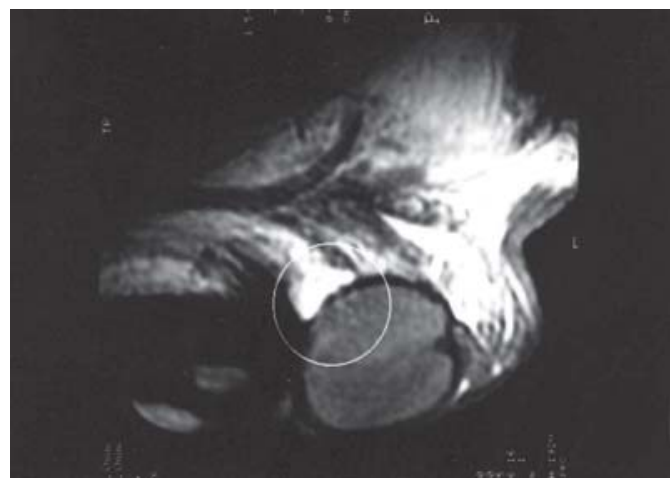

Mean age at presentation is 41.7 years (20 years to 88 years), including our patient.

Differential diagnosis of a testicular nodule includes benign tumors, such as schistosomiasis, and especially testicular cancer [13]. The classic presentation of testicular cancer is a painless lump in the testis, although many report diffuse pain, swelling or hardness in the scrotum [13].

Echographically, the typical lesion of testicular schistosomiasis is a well-delimited hypoechoic nodule with adjacent hyperechogenicity [2] However, any hypoechoic nodule should be considered malignant unless proven otherwise, since it is the most common radiographic pattern for testicular cancer [14]. MRI might be better than ultrasonography to show intratesticular abnormalities, however, neither technique allows differentiation between benign and malignant disorders; therefore biopsy is mandatory [15].

Treatment of testicular schistosomiasis includes treatment with oxamniquine or praziquantel, with nodule excision whenever possible. In five cases, an unnecessary orchiectomy was performed $[3,5-7,10]$. In our case, knowing that the patient was from an endemic area and since clinical-radiological data was compatible with schistosomiasis, testicle preservation was decided.

\section{References}

1. Ross A.G., Bartley P.B., Sleigh A.C., et al. Current concepts: Schistosomiasis. N Engl J Med 2002; 346:1212-20.
Figure 2. Schistosome ova with its lateral spine surrounded by granulomas $(400 \mathrm{X})$.

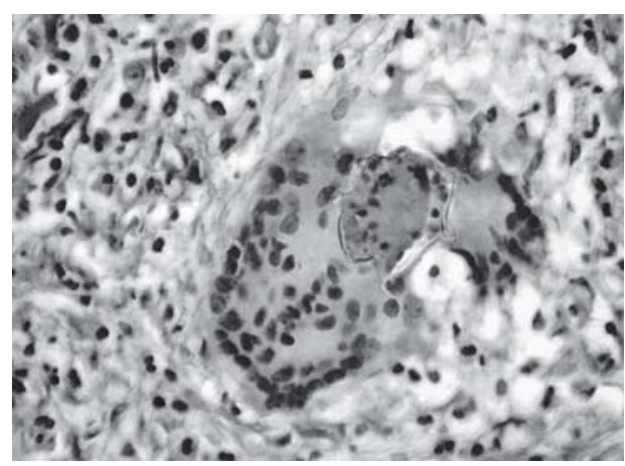

2. Lopes R.I., Lopes R.N., Leite K.R., et al. Testicular schistosomiasis simulating malignancy. Lancet Infect Dis 2003;3:556.

3. Mikhail N.E., Tawfic M.I., Hadi A.A., et al. Schistosomal orchitis simulating malignancy. J Urol, 1988;140:147-8.

4. Gonçalves E.C., Fonseca A.P., Pitella J.E. Frequency of schistosomiasis mansoni, of its clinicopathological forms and of the ectopic locations of the parasite in autopsies in Belo Horizonte, Brazil. J Trop Med Hyg 1995;98:289-95.

5. Bambirra E.A., Andrade J.S., Bamberg A., et al. Testicular schistosomiasis mansoni: a differential diagnostic problem with testicular neoplasms. Am J Trop Med Hyg 1986;35:791-2.

6. Buzzoni H.A., Saad F. Esquistossomose de testículo. Rev Paul Med 1980;96:79-80.

7. Elbadawi A., Davis R.S., Cockett A.T. Schistosomiasis presenting with testicular enlargement in an elderly male. Urology 1978; $12: 87-90$.

8. Franco Jr S.C., Arruda H.O. Esquistossomose de testículo. Rev Paul Med 1981;97:139-40.

9. Mitry N.F., Satti M.B., Tamimi D.M., et al. Testicular schistosomiasis. Br J Urol 1986;58:726-7.

10. Steinberger R.M., Lindsay K.G., Alassandri R., et al. Infarction of testicle and Schistosoma mansoni. Urology 1975;5:567-9.

11. Smits P.J., Van Helsdingen P.J. A rare localization of schistosomiasis. Neth J Surg 1980;32:117-8.

12. Mortati Neto N., Grando J.P., Moreira H.A. Testicular schistosomiasis mimicking tumor. Int Braz J Urol 2004;30:502-3.

13. Kinkade S. Testicular cancer. Am Fam Physician 1999;59:2539-44.

14. Lee Jr. F.T., Thornbury J.R. The Urinary Tract. In: Juhl J.H., Crummy A.B., Kuhlman J.E. Paul and Juhl's Essentials of radiologic imaging. 7. ed. Philadelphia, Lippincott-Raven, 1998. p. 635-735.

15. Thurnher S., Hricak H., Carroll P.R., et al. Imaging of the testis: comparison between MR imaging and US. Radiology, 1998; $167: 631-6$. 